\title{
Evaluation of the impact of pharmaceutical care for tuberculosis patients in a Secondary Referral Outpatient Clinic, Minas Gerais, Brazil
}

\author{
ANDREZA R.V. LOPES ${ }^{1}$, SILVANA S. DE MIRANDA², MARIA DAS GRAÇAS B. CECCATO ${ }^{1}$, \\ MICHELINE R. SILVEIRA ${ }^{1}$, NATÁLIA H. DE RESENDE ${ }^{1}$ and WÂNIA S. CARVALHO ${ }^{1}$ \\ ${ }^{1}$ Universidade Federal de Minas Gerais, Faculdade de Farmácia, Av. Antonio \\ Carlos, 6627, Pampulha, 31270-901 Belo Horizonte, MG, Brazil \\ ${ }^{2}$ Universidade Federal de Minas Gerais, Faculdade de Medicina, Av. Alfredo Balena, \\ 190, Sta. Efigênia, 30130-100 Belo Horizonte, MG, Brazil
}

Manuscript received on May 12, 2017; accepted for publication on September 11, 2017

\begin{abstract}
Pharmaceutical care is a professional practice seeking the responsible provision of drug therapy by identifying, resolving, and preventing Drug-Related Problems (DRP). The study aims to describe and evaluate the impact of pharmaceutical care given to patients being treated for tuberculosis (TB). Study concurrent, longitudinal, prospective conducted during pharmaceutical care in the TB outpatient clinic, Clinical Hospital, Federal University of Minas Gerais during the period August 2009 to July 2012. The Pharmacotherapy Workup proposed by Cipolle et al. (2004) was used. Statistical analyses were performed by $\mathrm{X}^{2}$ or Fisher exact test, as appropriate. A total of 62 patients were followed up, and 128 drug-related problems (DRP) were identified: $69.5 \%$ related to safety, $13.3 \%$ to effectiveness, $12.5 \%$ to indication, and $4.7 \%$ to treatment adherence, and $62.1 \%$ of the DRP were resolved. A total of 115 pharmaceutical interventions were performed. The impact of pharmaceutical care was satisfactory for $73.9 \%$ of patients with a resolution rate of $77 \%$. There was a greater impact on pharmaceutical care (index $\geq 0.50$ ) for those patients who were not smokers $(\mathrm{p}<0.05)$. The impact of pharmaceutical care was important, so the pharmacist should work alongside the multidisciplinary team to monitor treatment and perform interventions.
\end{abstract}

Key words: Pharmaceutical care, drug-related problems, tuberculosis, pharmacotherapeutic follow-up.

\section{INTRODUCTION}

Pharmaceutical care is a professional practice seeking the responsible provision of drug therapy by identifying, resolving, and preventing Drug-Related Problems (DRP). DRP are clinical problems related to indication, effectiveness, safety, and adherence

Correspondence to: Silvana Spindola de Miranda

E-mail: silvanaspindola@gmail.com and must be resolved to enable the provision of rational and appropriate treatment for the patient and avoid non-adherence to drug treatment (Hepler and Strand 1990, Cipolle et al. 2012).

Pharmaceutical care is accomplished through pharmacotherapeutic follow-up, and its main purpose is the achievement of therapeutic goals (cure, stabilization of a pathologic process, disease prevention, and symptom relief, among others) 
defined by both the professional and the patient and to improve the patient's quality of life (Cipolle et al. 2012).

With respect to the treatment of tuberculosis (TB), there are few published studies on pharmaceutical care for these patients in Brazil. Santos et al. (2006) reported the pharmacotherapeutic follow-up of patients with pulmonary TB in which seven patients were monitored, showing the importance of this approach.

TB remains one of the communicable diseases that most kills worldwide (WHO 2016). TB treatment is conducted over a long period of time and requires the use of various pills, which often have drug interactions and adverse reactions that can hamper adherence (WHO 2016). These effects may be minor and include mainly nausea, vomiting, abdominal pain, epigastric pain, itching, joint pain, peripheral neuritis, changes in appetite, sleep disorders, anxiety, and hyperuricemia. In general, these reactions do not require suspension of the use of TB drugs but rather the introduction of other drugs to reduce said reactions. Major effects include the appearance of rash, seizures, jaundice, and optic neuritis, among other symptoms, in which case, generally, the cessation of drug therapy is necessary (Vieira and Gomes 2008, Arbex et al. 2010, Maciel et al. 2010, Brasil 2011, Ferreira et al. 2013, Silva et al. 2017).

Given this context, the follow-up of TB patients by a multidisciplinary team is extremely important to achieve treatment success. This study therefore aimed to describe and evaluate the impact of pharmaceutical care given to patients undergoing TB treatment.

\section{MATERIALS AND METHODS}

This work was a concurrent longitudinal prospective study conducted in the TB secondary referral outpatient clinic, Clinical Hospital, Federal
University of Minas Gerais (Universidade Federal de Minas Gerais - UFMG), Belo Horizonte during the period August 2009 to July 2012. Approximately 30 patients with TB (first consultation) are treated at the clinic every year. They were included patients who were diagnosed with TB and who received pharmaceutical care, individuals older than 18 who agreed to participate and who signed the informed consent form participated in the study. The population was selected by convenience. Patients referred to another Basic Health Unit were excluded.

The follow-up of these patients was performed during consultation with pharmacists, and patients were then referred to a multidisciplinary health care team. The clinical parameters of measurement results for the control of disease were performed using clinical and laboratory data.

The Pharmacotherapy Workup questionnaire proposed by Cipolle et al. (2004) and standardized questionnaire for the detection of adverse reactions (Brasil 2008) were used to conduct pharmaceutical care through patient interview in three meetings.

For the patient's clinical evaluation, classification of associated diseases was performed using the International Statistical Classification of Diseases and Related Health Problems - ICD-10. This step was followed by classification of DRP in relation to indication (DRP 1 - unnecessary drug therapy and DRP 2 - requires additional drug therapy); effectiveness (DRP 3 - requires different drug product and DRP 4 - dosage too low); safety (DRP 5 - adverse drug reaction and DRP 6 - dosage too high); and adherence (DRP 7 - non-adherence) (Cipolle et al. 2004). The DRP classification was made during the patient evaluation through clinical evaluation and direct question to the patient.

When evaluating the pharmaceutical care offered to the patients followed-up in this study, the patient's health status was classified as positive or negative for each identified DRP. The result was considered positive in cases where the patient's 
health status was classified as resolved, stable, improved, or partially improved, whereas it was considered negative in cases where there was no improvement, or where there was worsening, failure, or death.

For each patient, an index of the impact of pharmaceutical care was calculated by dividing the number of DRP with positive results by the number of DRP that received intervention (Nascimento et al. 2011). The pharmaceutical care impact was classified satisfactory when the index was greater than or equal to $50 \%$ and unsatisfactory when the index was below $50 \%$. The resolution level was assessed by the median score of the pharmaceutical care impact index.

Interventions were divided into nonpharmacological and pharmacological. Nonpharmacological interventions included guidance on the proper use of drugs and their risks and referral to other health professionals, and pharmacological interventions included suspension of, addition of, or change in medication. Pharmacological interventions were agreed on by the pharmacist, physician, and patient when required.

With respect to the therapeutic profile, the therapeutic class of drugs used and number of drugs per patient were evaluated. All drugs were classified according to the first and second level of the Anatomical-Therapeutic-Chemical Classification System (ATC) (WHO 2011).

Patient-related characteristics were evaluated along with factors relating to the therapeutic profile and pharmaceutical care provided. Patientrelated characteristics included sociodemographic (gender, age, occupation, number of residents per household, place of residence); behavioral (smoking, alcoholism, and illicit drug use); and clinical (associated diseases and identified DRP) characteristics. Evaluation of smoking (Lolio et al. 1993) or illicit drug use was based on direct questioning of the patient. The validated CAGE (Cut-down, Annoyed by criticisms, Guilty, Eye- opener) instrument was applied to evaluate alcoholism (Mayfield et al. 1974) when the patient reported current use of alcohol or cases of abstinence for less than two years. It was considered smokers subjects who smoked more than 100 cigarettes, or five packs of cigarettes in their entire life and smoked at the time of interview (OPAS 1995).

Statistical analysis consisted of descriptive analysis of the data, including frequency distribution and measures of central tendency. Moreover, the association between the impact of pharmaceutical care and the characteristics selected was analyzed by $\mathrm{X}^{2}$ or Fisher exact test as appropriate. The significance level adopted for all analyses was 0.05 , with a confidence interval of $95 \%$. Data were analyzed using the Windows Statistical Package for Social Sciences (SPSS) software, version 21. The study was approved by the Ethics Committee of UFMG - COEP on July 16, 2009 under number 183/09.

\section{RESULTS}

A total of 74 patients with TB treated in the period, 12 were excluded (seven for transfer to another Unit of Health and five a change in diagnosis. Being eight women and four men). Therefore, 62 patients were followed up throughout the study representing $80 \%$ of patients treated in the Clinical Hospital. The age ranged from 18 to 66 years. The sociodemographic and behavioral characteristics presented in Table I show a majority of females (53.2\%). The majority of the population was between 41 and 60 years $(59.7 \%$; median $=51$ years; mean $\pm \mathrm{SD}=50.6 \pm$ 13.5 years), followed by the over 60 years group. Age ranged from 22 to 84 years.

Most patients resided in Belo Horizonte and its metropolitan region (83.9\%), and there was a median of three residents per household (mean \pm $\mathrm{SD}=3.0 \pm 1.6)$. Twenty-four patients (38.7\%) were smokers, six (9.7\%) were alcoholics, and only one reported using illicit drugs. 
TABLE I

Sociodemographic and behavioral characteristics of tuberculosis patients treated at the tuberculosis secondary referral outpatient clinic, Belo Horizonte, from August 2009 to July $2012(n=62)$.

\begin{tabular}{|c|c|c|}
\hline Variable & $\mathbf{N}$ & $\%$ \\
\hline \multicolumn{3}{|l|}{ Gender } \\
\hline Male & 29 & 46.8 \\
\hline Female & 33 & 53.2 \\
\hline \multicolumn{3}{|l|}{ Occupation } \\
\hline Yes & 48 & 77.4 \\
\hline No & 13 & 21.0 \\
\hline Did not answer & 1 & 1.6 \\
\hline \multicolumn{3}{|l|}{ Age group } \\
\hline $18-30$ & 6 & 9.7 \\
\hline $31-40$ & 9 & 14.5 \\
\hline $41-50$ & 16 & 25.8 \\
\hline $51-60$ & 21 & 33.9 \\
\hline$>61$ & 10 & 16.1 \\
\hline \multicolumn{3}{|l|}{ Area of Residence } \\
\hline $\begin{array}{l}\text { Belo Horizonte and } \\
\text { MRBH* }\end{array}$ & 52 & 83.9 \\
\hline Other cities & 10 & 16.1 \\
\hline \multicolumn{3}{|l|}{$\begin{array}{l}\text { Number of } \\
\text { residents in the } \\
\text { household }\end{array}$} \\
\hline $1-3$ & 39 & 62.9 \\
\hline$>3$ & 18 & 29.0 \\
\hline Did not answer & 5 & 8.1 \\
\hline \multicolumn{3}{|l|}{ Smoking } \\
\hline Yes & 24 & 38.7 \\
\hline No & 37 & 59.7 \\
\hline Did not answer & 1 & 1.6 \\
\hline \multicolumn{3}{|l|}{ Alcoholism } \\
\hline Yes & 6 & 9.7 \\
\hline No & 56 & 90.3 \\
\hline \multicolumn{3}{|l|}{ Use of illicit drugs } \\
\hline Yes & 1 & 1.6 \\
\hline No & 61 & 98.3 \\
\hline
\end{tabular}

*MRBH$=$ Metropolitan Region of Belo Horizonte.
The patients used a mean $\pm \mathrm{SD}=6.0 \pm 3.2$ drugs, with a median of six and range of 1 to 16 drugs. The most frequently used drugs were antiinfective for systemic use $(35.5 \%$ - 132/372), of these anti-infective, 118 were antimycobacterials $(89.3 \%-118 / 132)$, followed by alimentary tract and metabolism (21.2\% - 79/372) and the other therapeutic classes of drugs were $43.3 \%$ (161/372).

The pharmacological and non-pharmacological interventions used to resolve the DRP, $68.7 \%$ were positive, $17.4 \%$ were negative, and the results of 16 DRP were not evaluated (Table II). Among the DRP not evaluated, for $68.9 \%$ there was no information in the patient's records, $17.3 \%$ of cases were because the patient attended a single consultation (making it impossible to assess the outcome of the intervention) and $13.8 \%$ were due to a lack of feedback on the measures suggested by the pharmacist. DRP 3 and 6 were not found in the study.

In associated diseases, there was a mean $\pm \mathrm{SD}$ $=2.6 \pm 1.8$ and a median of 2 . A total of $27.4 \%$ of the patients had only TB; $25.8 \%$ had two concomitant diseases, followed by three, four, five, and seven concomitant pathologies in $21 \%, 17.7 \%, 6.5 \%$, and $1.6 \%$ of cases, respectively.

Most DRP were related to TB treatment drugs $(81.2 \%$ - 104/128), in relation to safety DRP for TB was found $84.6 \%(88 / 104)$ (Table III). The main DRP identified in the study were safety $(69.5 \%$ $89 / 128)$, mostly due to adverse TB drug reactions, followed by effectiveness (13.3\% - 17/128), indication $(12.5 \%-16 / 128)$ and adherence $(4.7 \%$ - 6/128); $62.1 \%$ of the DRP were resolved (Table III).

Regarding the relationship between the DRP and others diseases, most DRP were related to tuberculosis, followed by cardiovascular system diseases (e.g. Arterial Hypertension, Diabetes mellitus, among others). The proportion of DRP per system affected by others diseases are shown in Table III. 
TABLE II

Description of results by Drug-Related Problems category for tuberculosis patients that received intervention, August 2009 to July 2012, Belo Horizonte $(n=62)$.

\begin{tabular}{ccccc}
\hline Description & $* *$ Positive (\%) & $* * *$ Negative (\%) & Not evaluated (\%) & \multicolumn{2}{c}{ Total (\%) } \\
\hline DRP*1 & $4(100)$ & $0(0.0)$ & $0(0.0)$ & $4 \quad(100)$ \\
DRP2 & $9(75)$ & $1(8.3)$ & $2(16.7)$ & $12(100)$ \\
DRP4 & $12(70.6)$ & $2(11.8)$ & $3(17.6)$ & $17(100)$ \\
DRP5 & $52(66.7)$ & $17(21.8)$ & $9(11.5)$ & $78(100)$ \\
DRP7 & $2(50)$ & $0(0.0)$ & $2(50)$ & $4 \quad(100)$ \\
Total & $79(68.7)$ & $20(17.4)$ & $16(13.9)$ & $115(100)$ \\
\hline
\end{tabular}

*DRP $=$ Drug-Related Problems.

DRP indication (DRP 1 - unnecessary drug therapy and DRP 2 - requires additional drug therapy).

DRP effectiveness (DRP 4 - dosage too low).

DRP safety (DRP 5 - adverse drug reaction).

DRP adherence (DRP 7 - non-adherence).

**Considered positive: resolved, stable, improved and partially improved.

$* * *$ Considered negative: no improvement, worsening, failure and death.

TABLE III

Distribution of Drug-Related Problems per tuberculosis and system $(n=62)$.

\begin{tabular}{|c|c|c|c|c|c|}
\hline \multirow[t]{2}{*}{ Disease or system } & \multicolumn{5}{|c|}{ DRP } \\
\hline & Indication & Effectiveness & Safety & Adherence & Total \\
\hline Tuberculosis & 7 & 6 & 88 & 3 & 104 \\
\hline Cardiovascular System & 1 & 5 & 0 & 1 & 7 \\
\hline Metabolic diseases & 0 & 3 & 0 & 0 & 3 \\
\hline $\begin{array}{l}\text { Central Nervous } \\
\text { System }\end{array}$ & 1 & 1 & 0 & 1 & 3 \\
\hline Others & 7 & 2 & 1 & 2 & 12 \\
\hline Total & 16 & 17 & 89 & 6 & 128 \\
\hline
\end{tabular}

$\mathrm{DRP}=$ Drug-Related Problems.

For each patient was calculated one index of pharmaceutical care impact, splitting the DRP numbers with positive result per the DRP evaluated numbers. The values greater than or equal $50 \%$ of this index was considered satisfactory and the values below was considered unsatisfactory (Nascimento et al. 2011).

The pharmaceutical care impact index showed a mean $\pm \mathrm{SD}=0.66 \pm 0.38$ and a median of 0.77 . The index was calculated for 46 patients, as 13 patients had no DRP, and three did not have a DRP with a positive result, making it impossible to calculate the index. Pharmaceutical care was considered satisfactory for $73.9 \%$ of the patients and had a resolution level of $77 \%$. All patients in the study had a cure outcome.

The only significant association found was between smoking and the pharmaceutical care impact $(\mathrm{p}<0.05)$. No significant association was found for any other variable. The association between the pharmaceutical care impact and the "occupation" variable was only tested for 45 patients because, in addition to the factors described above, there was one patient with no data entered on the medical record. Only for alcoholism variable was analyzed using the Fisher exact test, for other variables, the characteristics select was analyzed using the Chi-square test. 


\section{DISCUSSION}

In this study, the majority of TB cases occurred in patients of working age, which corroborates the findings of other authors (Breen et al. 2006, Vieira and Gomes 2008, Ferreira et al. 2013). The age range of patients predominated in the study is over forty years old and is a predictive factor for the development of adverse reactions (Conde and Souza 2009, Brasil 2011). The elderly group requires the utmost care, since they are more susceptible to problems caused by adverse reactions and drug interactions due to polypharmacy (Baldoni et al. 2013). The higher likelihood of hepatic and renal function impairment in this age group can lead to treatment complications (Arbex et al. 2010).

This study differs from others in which the proportion of men is higher than women (Vasconcelos and Chatkin 2008, Maior et al. 2012, Alcântara et al. 2012). This difference is most likely due to the characteristics of the outpatient clinic during the study period. Considering the gender of the patient is warranted, as some studies have found a statistically significant higher nonadherence rate among male patients (Ferreira et al. 2005, Silveira et al. 2012). However, in another study, no significant association was identified between these variables (Campani et al. 2011).

The evaluation of TB patient contacts is important for diagnosing the disease or for determining the need to perform prophylactic treatment for TB. Therefore, assessing the number of residents per household is of utmost importance (Brasil 2011), as also shown in studies by Hartwig et al. (2008) and Barroso et al. (2004). Living alone is also a factor that predisposes a patient to abandon treatment, most likely due to lack of support and help during treatment. Campani et al. (2011) reported that people who did not live with their family members had a significant association with non-adherence to treatment. In this study, eight patients lived alone; however, all were discharged after cure, which shows that this characteristic did not influence the outcome.

Alcoholism is a predictive factor for nonadherence to TB treatment, as it increases the risk of hepatotoxicity, leaving patients more likely to experience adverse reactions. Thus, this factor may ultimately undermine treatment success (Munro et al. 2007, Arbex et al. 2010). Several studies have demonstrated the need to monitor patients who consume alcohol (Campani et al. 2011, Oliveira and Antunes 2012, Silveira et al. 2012, Viegas et al. 2017). This study included six alcoholic patients, but this characteristic did not influence treatment outcome because all patients were ultimately cured.

The monitoring of smokers is important because smoking is associated with recurrence of TB and mortality. In addition, smoking can contribute to generating more extensive sequelae by increasing the severity of injuries and delaying healing (Brasil 2011).

The use of antimicrobial was expressive, especially those used to TB treatment, because one of the inclusion criteria was be treating this disease. After the use of antimicrobials, drugs used in the alimentary tract and metabolism were the second most commonly used class, as such drugs are used to minimize adverse gastrointestinal reactions in the treatment of TB, which are very common.

The DRP found most frequently during followup was related to safety, as demonstrated by Santos et al. (2006), also conducted on TB patients in an outpatient setting. This result was expected due to the known adverse impacts of TB treatment (Arbex et al. 2010, Brasil 2011), which have also been shown in many other studies (Santos et al. 2006, Maciel et al. 2010, Ferreira et al. 2013).

DRP relating to adherence to pharmacological treatment were the least frequent, as observed by Cipolle et al. (2012), where less than $15 \%$ of DRP were related to non-adherence. Furthermore, studies have demonstrated that patients undergoing 
pharmacotherapeutic follow-up had higher rates of treatment adherence (Clark et al. 2007).

Most studies of pharmaceutical care, regardless of the pathology studied and the practice development scenario, have shown a higher proportion of DRP related to effectiveness compared to this study (Correr et al. 2009, Nascimento et al. 2009, Martins et al. 2013, Ramalho de Oliveira 2013). This result can be explained by the specific pathology and locality in which this study was developed, which is a referral outpatient clinic of a university hospital that provides thorough treatment to all patients.

The reasons for no evaluation of some DRP were the insufficient consultation numbers and the lack of counter reference for the cases that conduct consisted of patient referral for another professional, these reasons may interfere in DRP resolutions. However, Nascimento et al. (2011) have described the same reason.

Other diseases together with TB can determine many medications and increase the drug interaction possibility, so the pharmaceutical care becomes important.

The pharmaceutical care impact was considered satisfactory and resolute. In Nascimento et al. (2011) study, the solvability level was $67 \%$, considering like this study only the DRP resolution for the indicator calculation. However, in that study, the scenery was different, and with patients that were presenting a lot of diseases, and without TB. In Cipolle et al. (2004) study there was $90.6 \%$ of the clinical results partially improved, stable or resolved. Nonetheless, the study evaluated health status improvement in a global form, not only DRP resolution.

The DRP not identified in the study, the main reason being the non-recording of the evaluation on the patient's medical record. Other reasons were an insufficient number of consultations, making it impossible to evaluate the intervention, and a lack of cross-referencing for cases in which the process consisted of patient referral to another health professional for resolution of the DRP. These same reasons for non-evaluation were also described by Nascimento et al. (2011).

Most patients had between one and four associated diseases. This finding is important because the presence of certain diseases may require the use of large amounts of drugs for their treatment, and if so, there is a possibility of increased drug interactions.

The analysis of association between selected characteristics and the impact of pharmaceutical care, a significant association was found for the smoking variable, i.e., among patients with the greatest impact of pharmaceutical care (index $\geq$ 0.50 ), there was a higher proportion of patients who were not smokers.

The limitation of the study is the selection of the population for convenience, which can't be extrapolated to other sites, but reached $80 \%$ of TB cases treated in the period.

Only one study describes the pharmaceutical care focused on DRP in TB patients for the management of pharmacotherapy. The study included seven patients (Santos et al. 2006) and in our study were monitored 62 patients.

Considering the cases of TB abandonment in the country (10.4\%) (MS 2017) far from the goal recommended by WHO (below 5\%) (WHO 2016), the pharmacist plays an important role in patient education; in monitoring effectiveness treatment; in pharmacotherapy safety, and in promoting rational drug use (Mkele 2010).

In conclusion, the results demonstrate that pharmaceutical care is effective for identifying, resolving, and preventing DRP, especially because all patients obtained a cure. A rational decisionmaking process regarding drug therapy, it should be carefully documented, evaluated, improved, and deployed when following up patients using medication over the long-term. 


\section{ACKNOWLEDGMENTS}

The authors would like to thank the Fundação de Amparo à Pesquisa do Estado de Minas Gerais (FAPEMIG) for financial support.

\section{REFERENCES}

ALCÂNTARA CCS, KRITSKI AL, FERREIRA VG, FAÇANHA MC, PONTES RS, MOTA RS AND LEITÃO TMJS. 2012. Factors associated with pulmonary tuberculosis among patients seeking medical attention at referral clinics for tuberculosis. J Bras Pneumol 38(5): $622-629$

ARBEX MA, VARELLA MCL, SIQUEIRA HR AND MELLO FAF. 2010. Antituberculosis drugs: drug interactions, adverse effects, and use in special situations. Part 1: First-line drugs. J Bras Pneumol 36(5): 626-640.

BALDONI AO, AYRES LR, MARTINEZ EZ, DEWULF NLS, SANTOS V, OBRELI-NETO PR AND PEREIRA LRL. 2013. Pharmacoepidemiological profile and polypharmacy indicators in elderly outpatients. Braz J Pharm Sci 49(3): 443-452.

BARROSO EC, MOTARMS, PINHEIRO VGF, CAMPELO CL AND RODRIGUES JLN. 2004. Occurrence of active tuberculosis in households inhabited by patients with susceptible and multidrug-resistant tuberculosis. J Bras Pneumol 30(4): 401-408.

BRASIL. 2008. Ministério da Saúde, Controle da tuberculose: uma proposta de integração ensino serviço. Fundação Oswaldo Cruz. Escola Nacional de Saúde Pública Sergio Arouca. Rio de Janeiro, 348 p.

BRASIL. 2011. Ministério da Saúde, Manual de recomendações para o controle da tuberculose no Brasil. Brasília, 284 p.

BREEN RA ET AL. 2006. Adverse events and treatment interruption in tuberculosis patients with and without HIV co-infection. Thorax 61: 791-794.

CAMPANI STA, MOREIRA JS AND TIETBOHEL CN. 2011. Predictive factors of non-adherence to the treatment of pulmonary tuberculosis recommended by the Ministry of Health of Brazil in Porto Alegre (RS). J Bras Pneumol 37(6): 776-782.

CIPOLLE RJ, STRAND LM AND MORLEY PC. 2004. Pharmaceutical care practice: the clinician's guide, $2^{\text {nd }}$ ed., New York: McGraw - Hill, 394 p.

CIPOLLE RJ, STRAND LM AND MORLEY PC. 2012. Pharmaceutical care practice: the patient-centered approach to medication management, $3^{\text {rd }}$ ed., New York: McGraw - Hill, 697 p.

CLARK PM, KARAGOZ T, APIKOGLU-RABUS S AND IZZETTIN FV. 2007. Effect of pharmacist-led patient education on adherence to tuberculosis treatment. Am J Health-Syst Pharm 64: 497-505.

CONDE MB AND SOUZA GRM. 2009. Pneumologia e tisiologia: uma abordagem prática. São Paulo: Atheneu, $636 \mathrm{p}$.

CORRER CJ, PONTAROLO R, DE PAULA E SOUZA RA, VENSON R, MELCHIORN NA AND WIENS A. 2009. Effect of a Pharmaceutical Care Program on quality of life and satisfaction with pharmacy services in patients with type 2 diabetes mellitus. Braz J Pharm Sci 45(4): 809-817.

FERREIRA ACG, JÚNIOR JLRS, CONDE MBC AND RABAHI MF. 2013. Clinical outcomes of tuberculosis treatment using the basic regimen recommended by the Ministry of Health of Brazil with fixed-dose combination tablets in the metropolitan region of Goiânia. J Bras Pneumol 39(1): 76-83.

FERREIRA SMB, SILVA AMC AND BOTELHO C. 2005. Noncompliance with treatment for pulmonary tuberculosis in Cuiabá, in the State of Mato Grosso - Brazil. J Bras Pneumol 31(5): 427-435.

HARTWIG SV, IGNOTTI E, OLIVEIRA BFA, PEREIRA HCO AND SCATENA JH. 2008. Evaluation of surveillance of contacts of new tuberculosis cases in the state of Mato Grosso - Brazil. J Bras Pneumol 34(5): 298303.

HEPLER CD AND STRAND LM. 1990. Opportunities and responsibilities in pharmaceutical care. Am J Hosp Pharm 47: 533-543.

LOLIO CA, SOUZA JMP, SANTO AH AND BUCHALA CM. 1993. Prevalência de tabagismo em localidade urbana da região sudeste do Brasil. Rev Saúde Pública 27(4): 262265.

MACIEL ELN, GUIDONI LM, FAVERO JL, HADAD DJ, MOLINO LP, JONHSON JL AND DIETZE R. 2010. Adverse effects of the new tuberculosis treatment regimen recommended by the Ministry of Health of Brazil. J Bras Pneumol 36(2): 232-238.

MAIOR ML, GUERRA RL, CAILLEAUX-CESAR M, GOLUB JE AND CONDE MB. 2012. Time from symptom onset to the initiation of treatment of pulmonary tuberculosis in a city with a high incidence of the disease. J Bras Pneumol 38(2): 202-209.

MARTINS BPR, AQUINO AT, PROVIN MP, LIMA DM, DEWULF NLS AND AMARAL RG. 2013. Pharmaceutical Care for hypertensive patients provided within the Family Health Strategy in Goiânia, Goiás, Brazil. Braz J Pharm Sci 49(3): 609-618.

MAYFIELD D, MCLEOD G AND HALL P. 1974. The CAGE Questionnaire: Validation of a New Alcoholism Screening Instrument. Am J Psychiatry 131: 1121-1123.

MKELE G. 2010. The role of the pharmacist in TB management. S Afr Pharm J 77(2): 18-21. 
MS - MINISTÉRIO DA SAÚDE. 2017. Boletim Epidemiológico Secretaria de Vigilância em Saúde 48(8): $1-11$.

MUNRO SA, LEWIN SA, SMITH HJ, ENGEL ME, FRETHEIN A AND VOLMINK J. 2007. Patient adherence to tuberculosis treatment: a systematic review of qualitative research. PLoS Med 4(7): e238.

NASCIMENTO YA, CARVALHO WS AND ACÚRCIO FA. 2009. Drug-related problems observed in a pharmaceutical care service, Belo Horizonte, Brazil. Braz J Pharm Sci 45(2): 321-330.

NASCIMENTO YA, CARVALHO WS AND ACÚRCIO FA. 2011. Evaluation of a Pharmaceutical Care Service in Belo Horizonte (Brazil) Focusing on the Process and Clincial Results. Lat Am J Pharm 30(6): 1109-1116.

OLIVEIRA JF AND ANTUNES MBC. 2012. Announced abandonment of tuberculosis treatment in a family health unit in Recife - a user perspective. Rev APS 15(1): 4-13.

OPAS - ORGANIZACIÓN PANAMERICANA DE LA SALUD. 1995. Guías para el Control y Monitoreo de la Epidemia Tabaquica, 1995, $5 \mathrm{p}$.

RAMALHO DE OLIVEIRA D. 2013. Atenção Farmacêutica e serviços farmacêuticos. In: Medicamentos: Políticas, Assistência Farmacêutica, Farmacoepidemiologia e Farmacoeconomia. Acúrcio FA (Org), Belo Horizonte: Coopmed, p. 197-234.

SANTOS AC, PEREIRA DA, SILVA AO AND LOPES LC. 2006. Pharmaceutical follow-up in patients with pulmonary tuberculosis using the Dader method. Rev Ciênc Farm Básica Apl 27(3): 269-273.

SILVA VD, MELLO FCQ AND FIGUEIREDO SCA. 2017. Estimated rates of recurrence, cure, and treatment abandonment in patients with pulmonary tuberculosis treated with a four-drug fixed-dose combination regimen at a tertiary health care facility in the city of Rio de Janeiro, Brazil. J Bras Pneumol 43 (2): 113-120.

SILVEIRA CS, PASSOS PT, SODER TCH, MACHADO CPH, FANFA LS, CARNEIRO M, VALIM ARM AND POSSUELO LG. 2012. Epidemiological profile of patients abandoning tuberculosis treatment in a priority municipality of Rio Grande do Sul. Rev Epidemiol Control Infect 2(2): 46-50.

VASCONCELOS FCS AND CHATKIN MN. 2008. Epidemiological profile of Tuberculosis in Pelotas - Rio Grande do Sul - Brazil. Rev Bras Ciênc Saúde 12(3): 229 238.

VIEGAS AM, MIRANDA SS, HADDAD JP, CECCATO MG AND CARVALHO WS. 2017. Association of outcomes with comprehension, adherence and behavioral characteristics of tuberculosis patients using fixed-dose combination therapy in Contagem, Minas Gerais, Brazil. Rev Inst Med Trop São Paulo 59(1): 1-6.

VIEIRA DE AND GOMES M. 2008. Adverse effects in tuberculosis treatment: experience in an outpatient clinic of a hospital-school in the city of São Paulo. J Bras Pneumol 34(12): 1049-1055.

WHO - WORLD HEALTH ORGANIZATION. 2011. The Anatomical Therapeutic Chemical Classification index with Defined Daily Doses (ATC/DDD). Available at: <http://www. who.int/classifications/atcddd/en/>. Accessed April 08, 2017.

WHO - WORLD HEALTH ORGANIZATION. 2016. Global Tuberculosis Report. Available at: http://www. who.int/tb/publications/global_report/en/ Acessed June 2, 2017. 